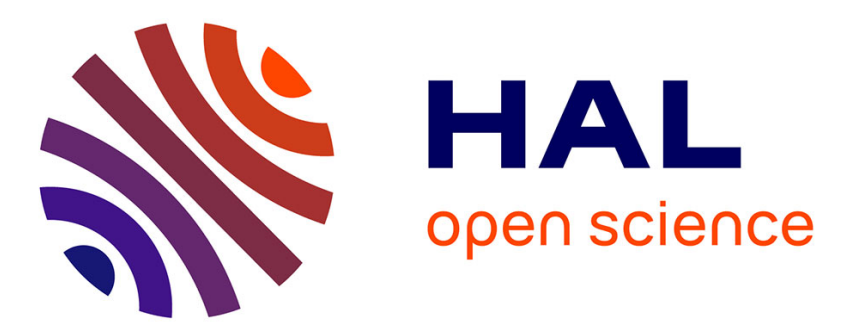

\title{
Sorafenib in combination with carboplatin and paclitaxel as neoadjuvant chemotherapy in patients with advanced ovarian cancer
}

\author{
Martin Pölcher, Meike Eckhardt, Christoph Coch, Matthias Wolfgarten, \\ Kirsten Kübler, Gunther Hartmann, Walther Kuhn, Christian Rudlowski
}

\section{To cite this version:}

Martin Pölcher, Meike Eckhardt, Christoph Coch, Matthias Wolfgarten, Kirsten Kübler, et al.. Sorafenib in combination with carboplatin and paclitaxel as neoadjuvant chemotherapy in patients with advanced ovarian cancer. Cancer Chemotherapy and Pharmacology, 2010, 66 (1), pp.203-207. 10.1007/s00280-010-1276-2 . hal-00573924

\section{HAL Id: hal-00573924 \\ https://hal.science/hal-00573924}

Submitted on 5 Mar 2011

HAL is a multi-disciplinary open access archive for the deposit and dissemination of scientific research documents, whether they are published or not. The documents may come from teaching and research institutions in France or abroad, or from public or private research centers.
L'archive ouverte pluridisciplinaire HAL, est destinée au dépôt et à la diffusion de documents scientifiques de niveau recherche, publiés ou non, émanant des établissements d'enseignement et de recherche français ou étrangers, des laboratoires publics ou privés. 


\title{
Sorafenib in combination with carboplatin and paclitaxel as neoadjuvant chemotherapy in patients with advanced ovarian cancer
}

\author{
Martin Pölcher • Meike Eckhardt • Christoph Coch • Matthias Wolfgarten • \\ Kirsten Kübler · Gunther Hartmann · Walther Kuhn · Christian Rudlowski
}

Received: 6 December 2009 / Accepted: 3 February 2010 / Published online: 5 March 2010

(C) Springer-Verlag 2010

\begin{abstract}
Purpose Sorafenib is a novel oral anticancer agent targeting signal transduction and angiogenic pathways through inhibitory effects against MAP kinases and vascular endothelial growth factor receptor-2. The objectives of this neoadjuvant phase II-trial in patients with advanced epithelial ovarian cancer were to assess the activity and tolerability of the combination therapy of carboplatin/paclitaxel with multi-target tyrosine kinase inhibitor sorafenib.

Materials and methods Patients with histologically proven stage IIIC or IV disease and large volume ascites were eligible. Enrolled patients received 2 of 6 cycles carboplatin (area under the curve 5) and paclitaxel $\left(175 \mathrm{mg} / \mathrm{m}^{2}\right)$ preoperatively and concomitant sorafenib $400 \mathrm{mg}$ twice daily. After four cycles of postoperative chemotherapy, a maintenance phase of single agent oral sorafenib through 1 year was planned. This phase II-study was planned with a sample size of 102 patients and progression-free survival as primary study endpoint.

Results Four patients were enrolled. After preoperative treatment and cytoreductive surgery, all patients were excluded from protocol due to severe toxicities. Three patients had life threatening events (cardiac output failure,
\end{abstract}

M. Pölcher · M. Eckhardt · M. Wolfgarten $\cdot$ K. Kübler $\cdot$ W. Kuhn · C. Rudlowski $(\bowtie)$

Department of Gynecology and Obstetrics,

Center for Integrated Oncology, Bonn University Medical Center,

University Hospital of Bonn, Sigmund-Freud-Str. 25,

53105 Bonn, Germany

e-mail: christian.rudlowski@ukb.uni-bonn.de

M. Eckhardt · C. Coch · G. Hartmann

Institute of Clinical Chemistry and Pharmacology,

Center for Integrated Oncology, University Hospital of Bonn,

Bonn, Germany myocardial infarction, anastomotic leak); two patients had primary progressive disease. The study was terminated on the basis of the recommendation of an independent data safety monitoring board.

Conclusion The addition of sorafenib to carboplatin/paclitaxel chemotherapy was not feasible within this neoadjuvant regimen in primary advanced ovarian cancer. Although the occurrence of serious adverse events might have emerged at random, a detrimental effect of preoperative study medication could not be denied. Further evaluations of sorafenib in ovarian cancer are warranted.

Keywords Sorafenib - Ovarian cancer - Neoadjuvant chemotherapy $\cdot$ Carboplatin $\cdot$ Paclitaxel

\section{Introduction}

Epithelial ovarian cancer is the leading cause of death from gynecologic malignancies [1]. Due to nonspecific initial symptoms, most cases of ovarian cancer are diagnosed at an advanced stage [2]. The current standard therapy for these patients is a combination of cytoreductive surgery followed by platinum- and taxane-based chemotherapy. Patients with International Federation of Gynecology and Obstetrics (FIGO) stage IIIC and IV disease have an unfavorable prognosis with 5-year survival rates varying from 19 to $33 \%$ depending on resectability and response to chemotherapy [3]. In ovarian cancer, numerous studies demonstrated the feasibility of preoperative chemotherapy in order to down-stage tumor load and to evaluate treatment response $[4,5]$. Given the efficacy plateau reached in the treatment of ovarian cancer with standard cytotoxic therapy, recent strategies have focused on molecular targets that inhibit mediators of angiogenesis. 
Sorafenib is an oral multi-kinase inhibitor targeting both tumor cells and the tumor vasculature [6]. As inhibitor of signal transduction, sorafenib acts on the Raf/MEK/ERK pathway [7] at the level of Raf kinase [8] and on tyrosine kinases vascular endothelial growth factor receptor-2 (VEGFR-2) and platelet-derived growth factor receptor $\beta$ (PDGFR- $\beta$ ). Sorafenib demonstrated single-agent activity in multiple phase I/II studies, and inhibited tumor growth in patients with refractory solid tumors of different sites. In addition, combination of chemotherapy and sorafenib showed partial response or stable disease.

The clinical benefit of sorafenib has been demonstrated in a randomized, double blind, placebo-controlled phase III study in patients with renal cell and hepatocellular carcinoma, leading to an approval of this medication $[9,10]$.

The potential activity of sorafenib in ovarian cancer is supported by preclinical studies [11]. Furthermore, patients with recurrent ovarian cancer were treated within a phase II-study [12] and within several phase I- studies in solid tumors [13].

This study was designed to assess efficacy of combination therapy of sorafenib and standard chemotherapy within the neoadjuvant setting. A special focus was put on preoperative response evaluation and on translational research projects for comparing pre- and posttreatment samples.

\section{Patients and methods}

This study included patients with histologically confirmed FIGO stage IIIC and IV epithelial ovarian cancer and an ascites volume of $500 \mathrm{ml}$ or more. The main exclusion criteria were mucinous cell type, debulking procedures during initial surgery, and signs of bowel obstruction.

Patients received carboplatin at area under the curve 5 and paclitaxel $175 \mathrm{mg} / \mathrm{m}^{2}$ intravenously in a three-week schedule and sorafenib was given $400 \mathrm{mg}$ twice daily (bid) orally. The treatment schedule is shown in the table. The primary endpoint was Progression-free survival. A clinically meaningful improvement was defined as a hazard ratio of 1.5 of historic treatment (PRIMOVAR study [5]) over sorafenib treatment. A total of 102 patients should be enrolled [14] (Table 1).

Adverse events were recorded and graded according to the National Cancer Institute Common Terminology Criteria for Adverse Events (NCI CTCAEv3.0). All patients provided informed consent, and the protocol was approved by the local ethic committee.

\section{Results}

From July through November 2007 four patients were enrolled. A diagnostic laparoscopy was performed to record
Table 1 Treatment plan of neoadjuvant combination therapy with carboplatin/paclitaxel and sorafenib

\begin{tabular}{lll}
\hline $\begin{array}{l}\text { Cycle } \\
\text { number }\end{array}$ & Medication & $\begin{array}{l}\text { Length } \\
\text { (days) }\end{array}$ \\
\hline 1 & $\begin{array}{l}\text { Carboplatin and paclitaxel d1 } \\
\text { sorafenib from d2 to d19 } \\
\text { Carboplatin and paclitaxel d1 } \\
\text { sorafenib from d2 to d11 } \\
\text { (rest sorafenib for 10 days before surgery) }\end{array}$ & 21 \\
2 & $\begin{array}{l}\text { Cytoreductive surgery } \\
\text { Recovery without chemotherapy } \\
\text { oP sorafenib treatment 14 days }\end{array}$ & 21 \\
Recovery & $\begin{array}{l}\text { Carboplatin and paclitaxel d1 } \\
\text { without administration of sorafenib }\end{array}$ & 21 \\
3 & $\begin{array}{l}\text { Carboplatin and paclitaxel on d1 } \\
\text { sorafenib from d2 to d19 }\end{array}$ & 21 \\
$4-6$ & $\begin{array}{l}\text { Maintenance phase with } \\
\text { sorafenib single agent }\end{array}$ & 28 \\
M1-M14 &
\end{tabular}

$d$ day, $O P$ operation, $M$ maintenance

the peritoneal spread and to confirm the diagnosis by taking biopsies of the peritoneal surfaces. After preoperative treatment and cytoreductive surgery, all patients were excluded from protocol due to severe (grade 3/4) toxicities. The study was stopped on the recommendation of an independent data safety monitoring board.

\section{Brief description}

The first patient was 72-year-old woman with a past medical history of diabetes complicated by a diabetic angiopathy and status post coronary artery bypass surgery 15 years ago. She presented with a stage IV disease and a symptomatic pleural effusion requiring multiple drainage. At the time of admission, cardiac examination was within normal limits. After the first cycle of chemotherapy and 2 weeks of study medication with sorafenib, she was admitted to the hospital with significantly impaired performance status, cardiac failure, edema and severe changes in electrolyte metabolism. The patients were subsequently admitted to the intensive care unit for close observation and diuretic treatment. The length of hospital stay was 7 weeks. She was excluded from the protocol and chemotherapy was continued with single agent carboplatin therapy. After a total of two preoperative cycles of chemotherapy, serum CA 125 levels decreased from 3,600 to $150 \mathrm{U} / \mathrm{ml}$. Cytoreductive surgery was performed without complications (no macroscopic residual disease) and systemic treatment was completed with four additional cycles of postoperative single agent carboplatin chemotherapy. Recurrence occurred after 13 months, and the patient died 21 months after initial diagnosis.

The second patient, 72 years old, presented with a stage IV disease with a malignant pleural effusion. Due to skin 
toxicity grade II, the sorafenib dose was reduced to $50 \%$. After 2 cycles of treatment, CA 125 serum level decreased from baseline 2,156 to $544 \mathrm{U} / \mathrm{ml}$. However, compared to the patterns of spread documented during laparoscopy, we found an increased number of peritoneal tumor sites at cytoreductive surgery. Residual tumor size: $>1 \mathrm{~cm}$. Suggesting platinum refractory tumor, further treatment proceeded with topotecan. Patient recurred after 12 months and died 24 months after initial diagnosis.

The third patient was 64 years old and presented with stage IIIC disease and a performance status ECOG 0 with an uneventful past medical history. Sorafenib was reduced after the first cycle due to skin toxicity grade II as recommended by the protocol. CA 125 baseline level dropped from 2,000 to $105 \mathrm{U} / \mathrm{ml}$. All visible tumors were reduced to less than $1 \mathrm{~cm}$. In the early postoperative course, she had a symptomatic posterior myocardial infarction. The conducted PTCA and anticoagulation treatment caused hemorrhage in the abdomen and necessitating re-laparotomy. She was excluded from the protocol and had a progression-free survival of 29 months after four postoperative cycles of single agent carboplatin. On last follow-up, there was no evidence of disease.

The fourth patient was 34 years old and presented with stage IIIC disease. After first cycle of therapy, dose reduction of sorafenib to $50 \%$ was required as skin toxicity grade II and gastrointestinal toxicity grade II was documented. CA 125 serum level decreased from $400 \mathrm{U} / \mathrm{ml}$ initially to $275 \mathrm{U} / \mathrm{ml}$. However, on laparotomy peritoneal carcinomatosis appeared more pronounced compared to initial laparoscopic findings. Cytoreductive surgery was performed, making small and large bowel resection and a partial bladder resection necessary (residual tumor: $\leq 1 \mathrm{~cm}$ ). An anastomotic leak of the rectosigmoid was diagnosed 5 days after surgery. Re-laparotomy was performed and had to be repeated after another week on account of peritonitis, leading to extensive resection of small bowel. (temporary abdominal closure and short bowel syndrome). Patient was excluded from the protocol, and chemotherapy was conducted with topotecan. She had an isolated recurrent tumor at the abdominal wall, which was treated with radiation therapy. Today she is alive 26 months after initial diagnosis and receives treatment of recurrent disease.

\section{Discussion}

We report a phase II-trial on oral sorafenib in combination with carboplatin and paclitaxel as neoadjuvant chemotherapy in the treatment of patients with advanced ovarian cancer. After enrollment of four patients, all patients were excluded due to adverse events. Three of them suffered lifethreatening events. Due to toxicity, dose reduction of the study medication sorafenib was necessary in all patients. Two patients were classified to have primary progressive disease. Based on these preliminary findings, an intolerable increase in toxicity and morbidity of oral sorafenib in combination with standard carboplatin/paclitaxel could not be excluded.

Most trials support sorafenib $400 \mathrm{mg}$ bid as the recommended dose for combination therapy [15]. Sorafenib as a single agent was generally well tolerated; most adverse events were mild to moderate in severity. Frequently reported drug-related adverse events at any grade included fatigue (40\%), anorexia (35\%), diarrhea (34\%), rash/desquamation (27\%), and hand-foot skin reaction (25\%). Drug-related toxicities of sorafenib have been also reported in phase I and II trials for several coadministered drugs, including oxaliplatin, gemcitabine and carboplatin/paclitaxel $[12,16]$. Recently, within a double blinded, placebocontrolled phase III-trial in patients with advanced melanoma, 270 patients were randomly assigned to receive intravenous paclitaxel $\left(225 \mathrm{mg} / \mathrm{m}^{2}\right)$ and carboplatin at area under the curve 6 according to a 21-day cycle and either placebo or oral sorafenib $400 \mathrm{mg}$ bid on days 2-19 [17]. Though dermatologic grade 3 adverse events were significantly increased in patients treated with sorafenib, hematologic and nonhematologic adverse events did not differ significantly between the placebo group and the patient group with sorafenib. The treatment was considered generally feasible particularly no continuous serious adverse events emerged within this treatment schedule, which represents a similar one compared to our study. Dose reduction was performed in 33\% (sorafenib group) and 10\% (placebo group). The combination therapy with oral sorafenib in this trial did not increase response rates or progression-free survival significantly over the standard treatment arm.

The serious adverse events in the current study raised the essential question, whether the neoadjuvant treatment could contribute to these side effects and whether this treatment after cytoreductive surgery could be less toxic. Ovarian cancer is an intraperitoneal disease with large tumor masses at presentation, especially in preselected advanced ovarian cancer patients with large volume ascites. Apoptotic and necrotic effects of antineoplastic therapy leads to degradation of large tumor cell masses, which may mediate an increased toxicity.

The combination of anticancer therapy and cytoreductive surgery might enhance postoperative morbidity and/or mortality. Targeting the VEGF pathway could impair wound healing and promote anastomotic leaks after bowel surgery. This was considered in the present treatment schedule and preoperative medication of sorafenib was stopped at least 10 days before surgery.

In two patients, progressive disease was diagnosed after neoadjuvant treatment: surgical exploration showed an 
increased number of peritoneal tumor implants. This was an unexpected finding, because in 43 patients treated at our institution within the PRIMOVAR trial, none of the patients were diagnosed with primary progressive disease [5].

Recent data demonstrates that some chemotherapeutic drugs can cause simultaneously host-mediated counterregulatory responses from the bone-marrow resulting in tumor angiogenesis and vasculogenesis. This mobilization effect in circulating endothelial progenitor cell levels may facilitate tumor cell repopulation during the common time intervals between the individual chemotherapy cycles [18]. Furthermore, Paez-Ribes et al. [19] reported that VEGF inhibition might play a role in regrowth of tumor, potentially influencing the progression of metastatic disease. Pretreatment of healthy mice with VEGF inhibitor sunitinib prior to intravenous inoculation of breast cancer cells led to more aggressive metastasis as well as a brief treatment after resection of the primary tumor. The underlying mechanisms remain to be explored but a withdrawal of antiVEGF therapy might promote vascular recovery and a rapid tumor re-growth [20]. A short time treatment in a neoadjuvant setting may lead accidentally to a stimulation of at least parts of the tumor or may promote metastasis. Prolonged intervals of treatment-discontinuation of antiangiogenic agents may also play a relevant role in the postoperative treatment of patients with residual disease or of patients with recurrent disease. Recently, several phase II studies were initiated analyzing a combination of sorafenib and carboplatin/paclitaxel for patients with primary ovarian cancer or recurrent disease and a combination of sorafenib and topotecan for patients with platinum resistant disease.

In conclusion, the current study was stopped because of serious adverse events. Considering the results in a recent reported trial [17], the findings of our study is probably based on random events. Future studies will be required to adjust the significance of antiangiogenic and tyrosinekinase inhibitory therapy in patients with ovarian cancer and the efficacy of concomitant treatment schedules or maintenance therapy.

Conflict of interest statement Christian Rudlowski: Research Funding (Bayer HealthCare AG, Deutschland). All other authors indicated no potential conflict of interest.

\section{References}

1. Jemal A, Siegel R, Ward E, Murray T, Xu J, Smigal C, Thun MJ (2006) Cancer statistics, 2006. CA Cancer J Clin 56:106-130

2. Cannistra SA (2004) Cancer of the ovary. N Engl J Med 351:2519-2529

3. Heintz AP, Odicino F, Maisonneuve P, Quinn MA, Benedet JL, Creasman WT, Ngan HY, Pecorelli S, Beller U (2006) Carcinoma of the ovary. FIGO 6th annual report on the results of treatment in gynecological cancer. Int $\mathbf{J}$ Gynaecol Obstet 95(Suppl 1):S161-S192

4. Vergote IB, Tropé CG, Amant F, Kristensen GB, Sardi JE (2008) EORTC-GCG/NCIC-CTG randomised trial comparing primary debulking surgery with neoadjuvant chemotherapy in stage IIIC-IV ovarian, fallopian tube and peritoneal cancer (OVCA). In: 12th biennial meeting, International Gynecological Cancer Society (IGCS), Bangkok

5. Pölcher M, Mahner S, Ortmann O, Hilfrich J, Diedrich K, Breitbach GP, Hoss C, Leutner C, Braun M, Mobus V, Karbe I, Stimmler P, Rudlowski C, Schwarz J, Kuhn W (2009) Neoadjuvant chemotherapy with carboplatin and docetaxel in advanced ovarian cancer-a prospective multicenter phase II trial (PRIMOVAR). Oncol Rep 22:605-613

6. Wilhelm SM, Carter C, Tang L, Wilkie D, McNabola A, Rong H, Chen C, Zhang X, Vincent P, McHugh M, Cao Y, Shujath J, Gawlak S, Eveleigh D, Rowley B, Liu L, Adnane L, Lynch M, Auclair D, Taylor I, Gedrich R, Voznesensky A, Riedl B, Post LE, Bollag G, Trail PA (2004) BAY 43-9006 exhibits broad spectrum oral antitumor activity and targets the RAF/MEK/ERK pathway and receptor tyrosine kinases involved in tumor progression and angiogenesis. Cancer Res 64:7099-7109

7. Thompson N, Lyons J (2005) Recent progress in targeting the Raf/ MEK/ERK pathway with inhibitors in cancer drug discovery. Curr Opin Pharmacol 5:350-356

8. Caraglia M, Tassone P, Marra M, Budillon A, Venuta S, Tagliaferri P (2006) Targeting Raf-kinase: molecular rationales and translational issues. Ann Oncol 17(7):vii124-vii127

9. Escudier B, Eisen T, Stadler WM, Szczylik C, Oudard S, Staehler M, Negrier S, Chevreau C, Desai AA, Rolland F, Demkow T, Hutson TE, Gore M, Anderson S, Hofilena G, Shan M, Pena C, Lathia C, Bukowski RM (2009) Sorafenib for treatment of renal cell carcinoma: final efficacy and safety results of the phase III treatment approaches in renal cancer global evaluation trial. J Clin Oncol 27:3312-3318

10. Llovet JM, Ricci S, Mazzaferro V, Hilgard P, Gane E, Blanc JF, de Oliveira AC, Santoro A, Raoul JL, Forner A, Schwartz M, Porta C, Zeuzem S, Bolondi L, Greten TF, Galle PR, Seitz JF, Borbath I, Haussinger D, Giannaris T, Shan M, Moscovici M, Voliotis D, Bruix J (2008) Sorafenib in advanced hepatocellular carcinoma. N Engl J Med 359:378-390

11. Gianpaolo-Ostravage C, Carter C, Hibner B (2001) Anti-tumour efficacy of the orally active raf kinase inhibitor BAY 43-9006 in human tumour xenograft models. Proc Am Assoc Cancer Res 42:923

12. Welch S, Hirte H, Schilder RJ, Elit L, Townsley C, Tinker L, Pond G, Afinec A, Wright JJ, Oza M (2006) Phase II study of sorafenib (BAY 43-9006) in combination with gemcitabine in recurrent epithelial ovarian cancer: a PMH phase II consortium trial. J Clin Oncol 24(18 Suppl):276S

13. Strumberg D, Awada A, Hirte H, Clark JW, Seeber S, Piccart P, Hofstra E, Voliotis D, Christensen O, Brueckner A, Schwartz B (2006) Pooled safety analysis of BAY 43-9006 (sorafenib) monotherapy in patients with advanced solid tumours: is rash associated with treatment outcome? Eur J Cancer 42:548-556

14. Dixon DO, Simon R (1988) Sample size considerations for studies comparing survival curves using historical controls. J Clin Epidemiol 41:1209-1213

15. Strumberg D, Richly H, Hilger RA, Schleucher N, Korfee S, Tewes M, Faghih M, Brendel E, Voliotis D, Haase CG, Schwartz B, Awada A, Voigtmann R, Scheulen ME, Seeber S (2005) Phase I clinical and pharmacokinetic study of the Novel Raf kinase and vascular endothelial growth factor receptor inhibitor BAY 43-9006 in patients with advanced refractory solid tumors. J Clin Oncol 23:965-972

16. Takimoto CH, Awada A (2008) Safety and anti-tumor activity of sorafenib (Nexavar) in combination with other anti-cancer 
agents: a review of clinical trials. Cancer Chemother Pharmacol 61:535-548

17. Hauschild A, Agarwala SS, Trefzer U, Hogg D, Robert C, Hersey P, Eggermont A, Grabbe S, Gonzalez R, Gille J, Peschel C, Schadendorf D, Garbe C, O'Day S, Daud A, White JM, Xia C, Patel K, Kirkwood JM, Keilholz U (2009) Results of a phase III, randomized, placebo-controlled study of sorafenib in combination with carboplatin and paclitaxel as second-line treatment in patients with unresectable stage III or stage IV melanoma. J Clin Oncol 27:28232830

18. Shaked Y, Henke E, Roodhart JM, Mancuso P, Langenberg MH, Colleoni M, Daenen LG, Man S, Xu P, Emmenegger U, Tang T, Zhu Z, Witte L, Strieter RM, Bertolini F, Voest EE, Benezra R,
Kerbel RS (2008) Rapid chemotherapy-induced acute endothelial progenitor cell mobilization: implications for antiangiogenic drugs as chemosensitizing agents. Cancer Cell 14:263-273

19. Paez-Ribes M, Allen E, Hudock J, Takeda T, Okuyama H, Vinals F, Inoue M, Bergers G, Hanahan D, Casanovas O (2009) Antiangiogenic therapy elicits malignant progression of tumors to increased local invasion and distant metastasis. Cancer Cell $15: 220-231$

20. Ebos JM, Lee CR, Cruz-Munoz W, Bjarnason GA, Christensen JG, Kerbel RS (2009) Accelerated metastasis after short-term treatment with a potent inhibitor of tumor angiogenesis. Cancer Cell 15:232-239 